\title{
PERILAKU PETANI DALAM PENGEMBANGAN PADI LOKAL VARIETAS PANDAN WANGI (Kasus di desa-desa sekitar kampung budaya , Kecamatan Warung Kondang Kabupaten Cianjur)
}

\author{
Yayat Sukayat, Dika Supyandi, Anne Charina
}

Departemen Sosial Ekonomi Pertanian Fakultas Pertanian Universitas Padjadjaran yayatsukayat@yahoo.com

\begin{abstract}
ABSTRAK
Beras pandan wangi, di Jawa Barat, menjadi salah satu varietas padi yang sudah sejak lama menjadi unggulan. Kekhasan yang dimiliki Pandan Wangi membuat beras Pandan Wangi diminati masyarakat menengah ke atas. Bahkan Dinas Pertanian Kabupaten Cianjur menetapkan Pandan Wangi sebagai komoditas unggul utama disamping tanaman palawija, sayuran, buahbuahan, dan tanaman hias (Podesta, 2009). Meskipun luas tanam dan produksi beras pandan wangi masih terbatas, dan cenderung tetap. Adanya ketidak sejalanan antara ikon di satu sisi, dan terbatasnya produksi dan luas tanam di sisi lain; ada apa dengan perilaku petaninya (pengetahuan, motivasi dan persepsi perannannya). Tujuan penelitian adalah untuk menggambarkan perilaku petani dalam usahatani padi lokal pandan wangi. Penelitian ini menggunakan desain kuantitatif, dengan metode yang di gunakan adalah Survey deskriptif. Dari hasil penelitian,secara teknik agronomis pengetahuan petani tentang budidaya padi masuk kategori baik; motivasi usahatani cenderung ke arah sosial; dan ada kebanggaan masih konsisten menanam pandan wangi.
\end{abstract}

Kata kunci : Pandan wangi, pengetahuan, motivasi, persepsi peran.

\begin{abstract}
Pandan Wangi rice, in West Java, has become one of the rice varieties that has long been a superior. Pandan Wangi rice has advantages in terms of aroma, taste and texture of fluffier rice. The peculiarities of the Pandan Wangi make Pandan Wangi rice prestigious and are of interest to the upper middle class. Even the Agriculture Office of Cianjur Regency established Wangi Pandanus as the main superior commodity in addition to crops, vegetables, fruits, and ornamental plants (Podesta, 2009). Although the area of planting and production of fragrant pandan rice is still limited and tends to remain. The existence of disparity between icons on the one hand, and limited production and planting area on the other side; what's wrong with the farmers' behavior (knowledge, motivation and perceptions of their role). The purpose of the study was to describe the behavior of farmers in the local pandan wangi rice farming. This research uses quantitative design, with the method used is descriptive survey. From the results of the study, the agronomic technique of farmers' knowledge of rice cultivation entered the good category; farming motivation tends to be social; and there is pride in consistently planting fragrant pandanus.
\end{abstract}

Keywords: fragrant pandanus, knowledge, motivation, perception of role. 


\section{PENDAHULUAN}

Laju pertumbuhan penduduk yang sulit untuk dibendung, telah mendorong berbagai upaya peningkatan produksi pangan. Kebutuhan pangan sampai saat ini mencapai $114 \mathrm{~kg}$ perkapita, menurun dari tahun sebelumnya yang mencapai $124 \mathrm{~kg}$ perkapita (BPS 2018). Namun secara kumulatif masih tetap tinggi yaitu mencapai 33,47 juta ton pada tahun 2018. Untuk memenuhi kebutuhan tersebut sebagian besar masih di dukung oleh penyediaan beras di Pulau Jawa, termasuk Jawa Barat. Di Jawa Barat ada lima kabupaten yang selalu meenyediakan kebutuhan beras cukup tinggi yaitu : Indramayu, Kerawang, Subang, Cianjur, Sukabumi.

Dalam perberasan, Cianjur sebagai penghasil beras, terkenal dengan beras cianjurnya, yang dikenal bukan hanya di tingkat regional nasional bahkan intenasional. Sebagai daerah dataran tinggi, cianjur tidak hanya mengembangkan padi varietas unggul baru (VUB), tapi juga bertahan dengan padi lokal yang sudah memiliki Indikasi Geografis (IG) yaitu padi/beras pandan wangi. Beras inilah yang menjadi icon kota cianjur. Beras pandan wangi memiliki beberapa keunggulan, salain aromanya yang seharum pandan, juga rasa, bahkan tekstur rasanya pulen. Harganya relatif unggul di banding dengan VUB, di tingkat petani berkisar antara Rp.18.000,00 sampai dengan Rp.20.000,00, dan di tingkat pedagang antara Rp. $25.000,00$ sampai dengan Rp.35.000,00/kg beras. Oleh karena itu wajar kalau beras pandan wangi ini lebih banyak di konsumsi oleh masyarakat lapisan menengah ke atas.

Beras pandan wangi dikenal dengan sebutan pandan wangi sejak tahun 1973. Konon katanya padi ini tumbuh kembang di cianjur sejak ahir tahun 1800 an, bahkan sejak tahun 1970 an sampai dengan tahun 1980 an, umumnya petani di cianjur menanam varietas lokal pandan wangi. Namun seiring dengan berkembangnya teknologi, dan di sosialisasikannya varietas unggul baru, mulalui program Bimas Inmas, petani yang menanam padi panda wangi mulai berkurang, terutama sejak tahun 90 an. Luas tanam pada saat ini hanya sekitar 14. $939 \mathrm{Ha}$, yang tersebar di 6 kecamatan.

Tabel 1. Daerah sentra Produksi Pandan Wangi, 2016

\begin{tabular}{|l|l|l|l|l|l|}
\hline Kecamatan & Kelompok & Luas sawah & \multicolumn{2}{|l|}{$\begin{array}{l}\text { Produksi } \\
\text { (Ton) }\end{array}$} & \multicolumn{2}{|l|}{ Produksi Beras (\%) } \\
\cline { 5 - 6 } & Tani & ( Ha) & Dikonsumsi & Di jual \\
\hline Warung Kondang & 28 & 3.200 & 760 & 46 & 54 \\
Cibeber & 20 & 2.985 & 315 & 69 & 31 \\
Cugenang & 14 & 2.174 & 357 & 80 & 20 \\
Cilaku & 31 & 2.574 & 210 & 68 & 32 \\
Cianjur & 14 & 1.206 & 183 & 98 & 2 \\
Campaka & 2 & 2.800 & 15 & 80 & 20 \\
\hline Jumlah & 78 & 14.939 & 1.876 & 73,5 & 26,5 \\
\hline
\end{tabular}

Sumber : Laporan Tahunan Dinas Pertanian Kab Cianjur.

Sejak tahun 2015 kondisi luas tanam ini bukannya bertambah, tapi terus mengalami penurunan, bahkan yang sangat drastis penurunannya yaitu di Kecamtan Warung 
kondang, tahun 2017 hanya tinggal 1.780 Ha. Fenomena menurunnya luas tanam ini telah mendorong Pemerintah Kabupaten Cianjur untuk terus berbenah diri, agar beras pandan wangi cianjur ini tetap lestari, diantaranya di ajukan sertifikasi indikasi geografis (IG), dan dikembangkannya kampung budaya pandan wangi.

Sertifikasi Indikasi Geografis (IG) untuk tanaman padi lokal pandan wangi sudah terealisasi pada tahun dan kampung budaya pandan wangi sudah dan sedang di bangun, oleh pemerintah daerah. Untuk merealisasikan kampung budaya tersebut, Pemda Cianjur merencanakan penyediaan lahan seluas $20 \mathrm{Ha}$, yang sudah terealisasi sekitar 4 Ha. Berikut bangunan rumah singgah, dilengkapi dengan lumbung tempat menyimpan hasil panen padi lokal pandan wangi.

Adanya gebrakan pemerintah dalam mendukung lestarinya padi lokal pandan wangi, yang didukung dengan kelembagaan berupa asosiasi petani pandan wangi, yang berfungsi mengontrol ke aslian pandan wangi di tingkat pedagang, belum menjadi stimulan bagi petani yang lainnya untuk menanam jenis padi pandan wangi. Kenapa demikian, karena bagi petani aspek pasar merupakan kunci keberlanjutan, karena tanam pandan wangi memerlukan waktu yang lebih lama di banding dengan padi varietas unggul baru (VUB). Artinya pasar bukan hanya ada tapi termasuk kesesuaian harga.

Dari fenomena tersebut di atas, ada hal yang menarik, meskipun waktu tanam lama, pasar terbatas dan harga tidak menarik , tapi masih terdapat beberapa petani yang berusaha menanam padi lokal pandan wangi. Bisa jadi usahatani padi merupakan usaha turunan, atau berusahatani karena hasil proses sosialisasi para leluhurnya dalam berstategi menghadapi kebutuhan hidupnya. Sebagai alternatif pencapaian tujuan, usahatani ini diterima oleh penerusnya bukan saja melembaga (institutionalisasi) tapi sampai mendarah dagimg (internalized), yang diwujudkan dalam bentuk cara, kebiasaan dan adat istiadat, atau sebagai pola tingkah laku (pattern of behavior). Dalam rasinalitas tindakannya, petani bertindak selalu memperhitungkan untung rugi, yang pada gilirannya keputusan - keputusan berusahatani rasionalisasi ekonomi lebih dominan. Timbul pertanyaan bagaimana tingkah laku petani dalam pengembangan padi pandan wangi sebagai alternatif pencapaian tujuan.

\section{METODOLOGI PENELITIAN}

Objek dalam penelitian ini adalah petani yang pernah dan yamg sampai saat ini masih bertahan untuk mengusahakan padi lokal pandan wangi, di desa-desa sekitar pusat pengembangan kampung budaya pandan wangi, di Kecamatan Warung Kondang yaitu Desa Tegal Lega, Desa Bunikasih, dan Desa Mekarwangi. Dalam penelitian ini dilakukan dengan menggunakan desain kuantitatif, dengan teknik survey (Neuman, 2015). Survey merupakan teknik pengumpulan data atau informasi secara tepat, akurat, dan terpercaya. Tujuannya adalah untuk menggambarkan secara cermat karakteristik dari suatu gejala atau masalah yang diteliti. Menurut Ulber Silalahi (2012) dengan menggunakan pertanyaan bagaimana berusaha mendapatkan, 
menyampaikan fakta-fakta dengan jelas dan lengkap.

Survey dilakukan pada petani yang masih konsisten menanam padi lokal pandan wangi, di Desa Tegal lega, Buni kasih dan Mekar wangi Kecamatan Warung Kondang Kabupaten Cianjur. Data yang digunakan yaitu data primer dan data secunder. Data primer diperoleh dari hasil wawancara dengan menggunakan alat bantu quesioner kepada petani pelaku usaha padi lokal pandan wangi.

Penentukan ukuran sampel,dilakukan dengan menggunakan teknik Simple Random Sampling (SRS). Dengan menggunakan rumus Slovin menggunakan nilai koreksi $10 \%$. Populasi petani yang menanam padi lokal pandan wangi sebanyak 780 petani. dengan menggunakan nilai koreksi $10 \%$ maka diperoleh ukuran sampel sebagai berikut :

$$
\mathrm{n}=\frac{\mathrm{N}}{1+\mathrm{N}(\mathrm{e})^{2}}
$$

Keterangan $\mathrm{N}=$ Ukuran populasi

$$
\begin{aligned}
\mathrm{n} & =\text { ukuran sampel } \\
\mathrm{e} & =\text { Nilai kritis } \\
\mathrm{n} & =\frac{780}{1+780(0.1)^{2}}
\end{aligned}
$$

$=88$ (ukuran sampel sebanyak 88 petani)

\section{HASIL DAN PEMBAHASAN}

Perilaku sebagai suatu tindakan terpola yang biasa dilakukan dalam rangka pemenuhan kebutuhannya. Perilaku petani dalam pemenuhan kebutuhan hidupnya terutama dalam pemenuhan kebutuhan ekonomi diwujudkan dalam kegiatan bertani. Cara dan kebiasaan yang dilakukan senatiasa di sejalankan dengan nilai dan pengetahuan yang dimilikinya. Skinner (1938), Noto Atmojo (1993), dan Robert Kwiek (1974). Memiliki pandangan yang sama tentang perilaku, yaitusuatu tindakan yang nyata karena adanya stimulus. Noto Atmojo (1993) perilaku ini ada yang tertutup dan ada yang terbuka. Perilaku tertutup, respon terhadap stimulus diwujudkan dalam bentuk pengetahuan, sikap, dan persepsi. Adapun perilaku terbuka ditunjukkan dengan tindakan-tindakan yang nyata. Stimulus yang muncul biasanya karena kebutuhan , dan kebutuhan ini biasanya identik dengan tujuan yang harus dicapai, dan hal itulah yang memotivasi seseorang untuk bertindak.

Perilaku petani pandan wangi, di daerah penelitian terbagi dua, yaitu perilaku pada pase produksi dan perilaku pasca produksi. Perilaku petani dalam pase produksi diungkap mulai penyediaan benih sampai dengan panen.

\section{Perilaku Pada Pase Produksi.}

Gambaran perilaku petani dalam pase produksi, diungkap melalui pengkajian pengetahuan dan kemampuan dalam melaksanakan penca usahatani, seperti penggunaan benih, pengolahan tanah, tanam, pemeliharaan, dan panen. Setiap unsur panca usaha diberi bobot nilai, yang secara keseluruhan (dari lima unsur tadi) nilai terendahnya 8 , dan tertinggi 24 . Melalui kategorisasi ,dibagi menjadi tiga kategori, yaitu kategori tidak baik bobot nilai 8 -13; kategori sedang, >13-18; dan kategori baik yaitu $>18-24$. Dari hasil analisis ternyata pengetahuan dan kemampuan petani pandan wangi dalam menjalankan panca usahataninya sebagian besar ( $57 \%$ ) sudah masuk dalam kategori 
baik dan sisanya (43\%) dalam kategori sedang.

Sebagian besar petani cukup menyadari, untuk menghasilkan produksi dan produktivitas padi pandan wangi yang baik, memerlukan benih yang baik pula. Benih yang baik, yaitu benih yang sudah disertifikasi oleh intansi terkait, di mana produktivitas, produksinya sudah teruji. Untuk benih padi pandan wangi yang baik hanya tersedia di balai benih dan MP3C

(Masyarakat Pelestari Padi Pandan Wangi Cianjur), yaitu lembaga yang terbentuk oleh petani pandan wangi yang memiliki fungsi kontrol baik dalam kualitas, harga maupun pasar. Petani padi pandan wangi,

\begin{tabular}{|l|l|l|}
\hline \multirow{2}{*}{ Penggunaan dan Sumber Benih } & \multicolumn{2}{|l|}{$\mathrm{N}=88$} \\
\cline { 2 - 3 } & $\mathrm{N}$ & $\%$ \\
\hline 1.Benih Unggul Dari Balai Benih & 50 & 57 \\
(bersertifikat) & 38 & 43 \\
2. Benih Unggul Usaha sendiri & 0 & 0 \\
atau dari tetangga & & \\
3. Benih Hasil panen langsung & & \\
\hline Jumlah & & \\
\hline
\end{tabular}

umumnya memiliki pengetahuan yang sangat baik, dalam penyediaan benihnya. Sebagian besar petani sebelum melakukan tebar benih selalu di awali dengan seleksi benih, apakah benih ini baik atau tidak, dan benih yang di gunakan umumnya masuk kategori unggul (Tabel 2).

Tabel 2. Penggunaan Benih Padi Unggul Pandan Wangi.

Dari tabel tersebut, menginformasikan menginformasikan bahwa petani yang bertahan mengusahakan pandan wangi sangat menjaga keaslian dan produktivitasnya. Hal ini sejalan dengan yang disampaikan Eman Faturoman dan Sumarno (2017). Bahwa penggunaan benih yang bermutu, bersertifikat akan meningkatkan produktivitas. Hal ini pun di dukung oleh pendapat Metaia et al. (2011) dan Diaz et al. (1998), yang intinya benih yang bermutu dan bersetifikat akan meningkatkan produktivitas dan terjaga secara genetis. Untuk keperluan satu Ha petani harus menyediakan benih sebanyak 80 kg@ Rp.20.000,00 atau sebesar Rp.800.000,00.

Unsur lain yang tidak kalah penting dalam meningkatkan produksi dan produktivitas yaitu pengolahan tanah. Pengolahan tanah biasanya dilakukan untuk memperbaiki kondisi tanah, baik tekstur maupun struktur tanah. Pengolahan tanah yang dilakukan oleh petani yang menanam padi lokal pandan wangi di daerah penelitian ada yang dua kali dengan adanya jeda waktu dan ada yang dua kali tapi sekali gus (petani nyebutnya satu kali). Menurut petani sebetulnya pengolahan tanah dua kali dengan adanya jeda waktu dan tidak, itu cukup berpengaruh terhadap kondisi tanah. Dengan adanya jeda, ada dua manfaat bagi lahan, pertama lahan istirahat, ke dua membalikan tanah dan membiarkannya agar tersinari matahari (istilahnya supaya kapoe).

Petani yang konsisten dalam mengolah tanah dua kali dengan jeda, biasanya dilakukan oleh petani - petani yang memiliki lahan relatif luas, atau di atas luas rata-rata $(0,485 \mathrm{Ha})$ yang jumlahnya hanya sekitar 10 persen. Sisanya sekitar 90\% petani melakukan pengolahan tanah dua kali tanpa jeda, atau setelah diwuluku langsung digaru dan dicaplak untuk siap tanam. Dari kejadian tersebut, ada beberapa hal sebagai wujud rasionalisasi petani dalam budayanya. Pertama, ketika mereka mengolah dua kali dengan jeda, 
petani masih terinspirasi hasil sosialisasi orang tuanya, dalam menjaga kesuburan tanah atau lestarinya sumberdaya alam. Cara yang mereka lakukan meruppakan warisan dari leluhurnya; ke dua, bagi petani yang melakukan oleh tanah dua kali tanpa jeda, intinya efektif dan efisien.

Proses selanjutnya setelah pengolahan tanah, mulai dari wuluku, garu dan caplak (membuat ukuran tanam) yaitu proses tanam. Dalam proses tanam, petani pandan wangi sangat memperhatikan waktu tanam yaitu bulan januari dan bulan juli, dengan pola tanam sebagai berikut : (gambar 1)

\begin{tabular}{|l|l|l|l|l|l|l|l|l|l|l|l|}
\hline \multicolumn{1}{|l|}{ Bulan } \\
\hline 7 & 8 & 9 & 10 & 11 & 12 & 1 & 2 & 3 & 4 & 5 & 6 \\
\hline
\end{tabular}

Gambar 1. Pola Tanam Padi

Menurut petani pada bulan tersebut, diperkirakan air akan tersedia, sehingga pada pase pertumbuhan tanaman tidak terganggu. Sebagian besar petani $(56 \%)$ menanam padi pandan wangi setahun dua kali, sisanya ada yang tanam pandan wangi 3 kali dalam dua tahun (1\%), dan $43 \%$ petani tanam pandan wangi satu tahun satu kali bahkan ada yang sekali dalam dua tahun itupun bergantung kebutuhan. Jarak tanam secara umum yang digunakan petani untuk tanam pandan wangi yaitu 30 x $30 \mathrm{~cm}$. Namun bagi petani yang konsisten tanam setahun dua kali (46\%), selain jarak tanam yang sama, per tiga atau empat rumpun dikosongkan satu baris. Fungsinya adalah untuk memudahkan proses asimilasi, dimana penyinaran matahari bisa sampai batang dan tanah. Hal ini dilakukan karena selain tanaman nya tinggi, juga jumlah anakannya sangat banyak. Ini dikenal dengan tanam sistem legowo.
$30 \mathrm{~cm}$

$\begin{array}{llll}\mathrm{X} 1 \longleftrightarrow \mathrm{X} 4 & \mathrm{X} 5 & 40-60 \mathrm{~cm} \mathrm{X6} \\ \mathrm{X} & \mathrm{X} & & \\ \mathrm{X} 2 & \mathrm{X} & & \\ \mathrm{X} 3 & \mathrm{X} & \mathrm{X}\end{array}$

Jarak tanam antara X1 dengan $\mathrm{X} 2=15$ $\mathrm{cm}$, antara $\mathrm{X} 1$ dengan $\mathrm{X} 5=30 \mathrm{~cm}$ dan antara X5 ke X5 bisa antara 40 sampai dengan $60 \mathrm{~cm}$, bergantung posisi lahan terbukanya dari posisi penyinaran.

Langkah berikut yang biasa dilakukan oleh petani pandan wangi yaitu pemeliharaan yang meliputi pemupukan, penyiangan dan pengendalian hama penyakit. Pemupukan dilakukan mengikuti cara yang biasa dilakukan pada varietas unggul baru (menggunakan pupuk kimia seperti Urea, TSP, NPK dan SP36), yang membedakannya adalah dosis perhektarnya, untuk padi lokal pandan wangi dosisnya lebih kecil/sedikit dibanding dengan dosis pupuk VUB atau 1 :2. Sebagian kecil (10\%) selain menggunakan pupuk kimia juga sebagai pupuk dasar digunakan pupuk organik, yang jumlahnya berkisar antara 1 sampai dengan 1,5 ton per hektar, atau mengikuti model LEISA (Low Eksternal Input Sustainable Agriculture), yang pada gilirannya akan beralih ke organik.

Padi pandan wangi sedikit rentan oleh hama dan penyakit, serangan yang sering dihadapi yaitu busuk batang, oleh karena itu pemberantasan hama penyakit kerap dilakukan (dua kali) dengan menggunakan obat-obat kimia seperti Furadan, Matador, Desis dan Arivow. Selain dilakukan pemupukan dan pemberantasan hama penyakit, petanipun melakukan penyiang dua kali dalam satu musim, yaitu pada 
pertumbuhan dan menjelang fase pembuahan (fase generatif).

Langkah terakhir yang dilakukan dalam fase produksi yaitu proses panen. Panen dilakukan ketikan padi sudah kuning merata, dan pelaksanaannya ketika matahari sudah muncul (teu aya cai ibun) . maksudnya supaya ketika dipanen padi tidak rontok.

Dari fenomena yang muncul dalam fase produksi, pengetahuan petani secara teknis, sosial dan ekonomis dijadikan dasar dalam pengambilan keputusan pengembangan usahatani pandan wangi. Perhatian terhadap kesuburan alam (Nature) mulai dari ketinggian, kemiringan dan jenis tanah, menjadi dasar dalam menentukan waktu dan pola tanam. Adanya sebagian petani yang mulai mengadopsi teknologi ramah lingkungan, merupakan wujud rasionalisasi tindakan dalam proses produksi untuk menjaga keberlanjutannya. Baik berlanjut secara ekonomi, sosial maupun budaya. Dengan demikian perilaku petani dalam pengembangan usahatani pandanwangi, menganut nilai-nilai konvensional (teknologi modern) dan nilai-nilai yang bersumber dari leluhurnya (tradisional), dikominasikan dijadikan sebagai kerangka landasan bagi petani dalam pengambilan keputusan.

\section{Perilaku Pasca Produksi.}

Apa kebiasaan petani yang dilakukan setelah panen, atau padi terkumpul.

Ternyata sama dengan ketika mereka panen padi varietas unggul baru (VUB) ,artinya ada yang di jual dan ada yang dikonsumsi (Tabel 3).

Tabel 3. Pemanfaatan hasi panen

\begin{tabular}{|l|l|l|}
\hline & $\mathrm{n}$ & $\%$ \\
\hline 1. Konsumsi saja & 30 & 34,09 \\
2. Konsumsi + di jual & 12 & 13,64 \\
3. seluruhnya untuk di jual & & \\
a. bentuk GKP & 28 & 31,82 \\
b. bentuk GKG & 10 & 11,36 \\
c. bentuk beras & 8 & 9,09 \\
\hline Jumlah & 88 & 100 \\
\hline
\end{tabular}

Sebagian besar dari petani dalam mengusahakan padi lokal pandan wangi, hanya untuk di jual, sisanya untuk di konsumsi. Dalam menjual hasilpun umumnya bervariasi ada yang dalam bentuk gabah GKP dan GKG, ada juga yang di jual dalam bentuk beras. Cara yang dilakukan ini biasanya berangkat dari pengalaman. Misal nya seperti yang disampaikan oleh Pa Ibrahim "Wah Pak di ical parenamah, komo pare nembe kenging panen ku tangkulak ditampina mung antawis Rp.4500 dugi ka Rp.5000, /kg ranggeuy. Relatif sami sareng pare varietas enggal, numawi mending di ical beasna". "Pak kalau dijual dalam bentuk gabah kering panen harganya hanya antara Rp.4500,00 sampai dengan Rp.5000,00. mending dijual dalam bentuk beras".

Pendapat ini sama dengan yang disampaikan H Abdulah “di ical parenamah teu ka hartos / kalua di jual dalam bentuk gabah tidak berarti”. Hal tersebut bisa dipahami, harga gabah GKP di tingkat petani hanya di beli Rp.4500Rp.5000 dan kalau di jual kering atau GKG Rp.8000 - Rp.10.000. Tapi kalau di jual dalam bentuk beras bisa mencapai Rp.18.000 sampai dengan Rp.20.000 di tingkat petani. Untuk menghasilkan $1 \mathrm{~kg}$ beras yaitu diperoleh dari $3 \mathrm{~kg}$ gabah GKP (Rp.4500). Perhitungan singkat persi petani sebagai berikut: $1 \mathrm{~kg}$ GKP akan menhasilkan beras 0,4 kg, $3 \mathrm{~kg}$ GKP menghasilkan 1,2 kg beras, harga $1 \mathrm{~kg}$ 
beras Rp.20.000,00 atau Rp.24.000,00.

Biaya untuk jemur di tambah ongkos giling Rp.4000,00 sehingga yang diterima sekitar Rp.20.000. Jadi kalau di jual gabah hanya Rp.13.500 atau Rp.15.000, tapi kalau di jual dalam bentuk beras mendapat Rp.20.000, artinya ada profit sebesar Rp.5000. Pengetahuan inilah yang menyebabkan perilaku petani berbeda mulai dari intensitas tanam, waktu tanam, cara tanam dan cara menjual.

Ketika petani berperilaku, tidak hanya atas dasar pengettahuan saja tapi juga terkait dengan persepsi dan motivasi dalam mengusahakan padi lokal pandan wangi ini. Peraepsi sendiri merupakan tanggapan terhadap sesuatu atas dasar pengetahuan dari penglihatannya dan pengalamannya. Morgan, 1966, Hebb,1972, dan Mulyana 2002 dalam Notoatmojo 1997. pada intinya persepsi merupakan hasil interprestasi atas penglihatan dan pengalaman yang diwujudkan dalam bentuk tanggapan. Untuk mengkaji persepsi petani terhadap usahatani pandan wangi, di ajukan pertanyaan yang menunjuk kepada : proses produksi, pasar dan Harga. (Tabel 3)

\section{Tabel 3. Persepsi Petani Pandan Wangi}

\begin{tabular}{|l|c|c|c|c|c|c|}
\hline Unsur unsur & $\mathrm{N}$ & \multicolumn{5}{|c|}{ Persepi Petani (\%) } \\
\cline { 3 - 7 } $\begin{array}{l}\text { terkait } \\
\text { usahatani }\end{array}$ & & SM & M & S & Sl & SSl \\
pandan wangi & & & & & & \\
\hline Proses & 88 & & 100 & & & \\
produksi & 88 & & 18 & & 82 & \\
Pasar & 88 & & & 8 & 12 & 80 \\
\hline
\end{tabular}

\section{Harga}

Persepsi petani terhadap usahatani padi lokal pandan wangi , terutama dalam proses produksi tidak sulit, walaupun agak berbeda dengan usahatani VUB terutama waktu panen, hanya yang jadi persoalan bagi petani adalah masalah harga terutama di pedagang pengumpul sering di samakan dengan padi VUB. dan pasarnyapun terbatas. Itulah yang membuat kurang tertarik.

Kondisi inipun erat kaitannya dengan motivasi petani dalam menanam padi tersebut. Motivasi petani atau dorongan petani untuk menanam padi pandan wangi ini berbeda-beda ,bergantung pada pengetahuan dan pengalamannya. Wahjosumidjo (1987), Gibson (1994), Harianja (2002) dan Robbins (2008). Pada intinya sama mengungkapkan bahwa motivasi merupakan faktor pendorong bagi seseorang untuk berperilaku. Bahkan Maslow mengkaitkan dengan kebutuhan manusia. Oleh karena itu dalam kegiatan usahatani padi lokal pandan wangi, motivasi petani bisa berasal dari ekonomi atau sosial dan psikis.

Dari hasil penelitian motivasi petani menanam padi pandan wangi umumnya berbeda-beda. Yang membuata beda yaitu seberapa jauh pengetahuan dan pengalaman ini melembaga dalam pikiran dan perasaannya (Tabel 4).

Tabel 4. Motivasi Petani dalam Berusahatani Pandanwangi (\%)

\begin{tabular}{|l|l|l|l|l|l|}
\hline Motivasi Petani & N & $\begin{array}{l}3 \text { x dalam } \\
\text { dua tahun }\end{array}$ & $\begin{array}{l}2 \text { x dalam } \\
\text { setahun }\end{array}$ & $\begin{array}{l}1 \text { x dalam } \\
\text { setahun }\end{array}$ & $\begin{array}{l}\text { Kadang- } \\
\text { kadang }\end{array}$ \\
\hline $\begin{array}{l}\text { Ekonomi : } \\
\begin{array}{l}\text { Menguntungkan } \\
\text { Tidak menguntungkan }\end{array}\end{array}$ & & V & V & & \\
$\begin{array}{l}\text { Sosial : } \\
\text { Menjaga kebiasaan orang tua } \\
\text { Mengikuti program }\end{array}$ & & V & & & \\
\hline
\end{tabular}




\begin{tabular}{|l|l|l|l|l|l|}
\hline Psikis : & & & V & \\
Menjaga kebiasaan tanam & & & & & \\
Pandanwangi & & & & \\
Menjaga eksistensi kota cianjur & & & V & & \\
penghasil pandanwangi & & & & \\
\hline
\end{tabular}

Dari tabel 4. Diperoleh informasi bahwa motivasi petani konsisten menanam pandan wangi atau kadang-kadang tanam padi pandan wangi terkait dengan masalah ekonomi. Bagi yang konsisten ternyata menanam pandan wangi cukup menguntungkan, dan juga menjaga ebiasaan orang tua, sedangkan bagi yang kadang-kadang menanam, juga terkait masalah ekonomi, harga yang tidak menentu. Tidak sedikit petani yang menanam pandan wangi karena program yang sedang di usung pemerintah, mudahmudahan harga dan passar bisa terjaga sekaali gus menjaga eksistensi kota ci anjur yang sudah terkenal dengan beras cianjur.

\section{KESIMPULAN}

Dari pembahasan di atas, maka dapat di simpulkan bahwa perilaku petani dalam mengusahakan padi lokal pandan wangi diwujudkan dalam aktivitas dalam panca usahatani,dimana sebagian besar petani sudah masuk dalam kategori baik. Perilaku petani dalam menanam padi pandan wangi ,sebagian besar menanam 2 kali dalam setahun, sisanya hanya satu kali dalam setahun atau kadang-kadang menanam. Perilaku menjual hasil ada yang menjual dalam bentu gabah, ada yang menjual dal bentuk beras. Persepsi petani menanam pandanwangi, dalam usahataninya tidak sulit yang sulit adalah pasar dan harga. Motivasi petani menanam pandan wangi karena motivasi ekonomi (keuntungan) dan motivasi sosial (menjaga eksistensi diri dan lokasi, juga program pemerintah daerah).

\section{DAFTAR PUSTAKA}

Diaz,C.,Hossain,M.,Merca,S.,Mew,T. 1988 Seed Quality an effec on rice yield : finding from Farmer Participatoty experiment in Luzon. Pilippines J.Crops Sci 23 (2) 111 119

Erman Faturahman dan Sumarno, 2017

Pusat Penelitian dan Pengembangan Tanaman Pangan . System Perbenihan formal dan Informal Tanaman Pangan

Hariandja, Marihot Tua Efendi, 2002. Manajemen Sumberdaya Manusia . Grasindo Jakarta

Metaia, A., N. Jamora., P. Moya., S

Fransisco, and D.Dawe. 2011.

Sources of Decade rice yield

Growth in the philippines.

Philippina Journal of Crop Science ,36 (2) 20 -29

Nasution, Fadli Heriadi., J. Ginting dan B. Siagian 2013. Tanggap pertumbuhan produksi padi gogo Varietas Situ Bagendit Terhadap Pengolahan tanah, dan Fequensi penyimpangan yang berbeda. On line agroekoteknologi 1 (2). 24 36

Notoatmojo,1997 Pengantar Ilmu Perilaku. Jakarta. 
Wahjosumidjo,1987 Kepemimpinan dan

Motivasi. Ghalia Indonesia` 